\title{
Role of sex hormones in modulating myocardial perfusion and coronary flow reserve
}

\author{
Ahmed Haider ${ }^{1,2} \cdot$ Susan Bengs ${ }^{1,2} \cdot$ Angela Portmann $^{1,2} \cdot$ Alexia Rossi $^{1,2} \cdot$ Hazem Ahmed $^{3} \cdot$ Dominik Etter $^{1,2}$. \\ Geoffrey I. Warnock ${ }^{1,2} \cdot$ Nidaa Mikail, $^{1,2}$. Muriel Grämer ${ }^{1,2} \cdot$ Alexander Meisel $^{1,2} \cdot$ Livio Gisler $^{3}$. Caitlin Jie ${ }^{3}$. \\ Claudia Keller $^{3}$ - Sebastian Kozerke ${ }^{4} \cdot$ Bruno Weber $^{5} \cdot$ Roger Schibli $^{1,3} \cdot$ Linjing Mu $^{1,3}$. Philipp A. Kaufmann ${ }^{1}$. \\ Vera Regitz-Zagrosek ${ }^{6,7} \cdot$ Simon M. Ametamey ${ }^{3} \cdot$ Catherine Gebhard $^{1,2}$
}

Received: 6 September 2021 / Accepted: 31 December 2021 / Published online: 13 January 2022

(c) The Author(s) 2022

\begin{abstract}
Background A growing body of evidence highlights sex differences in the diagnostic accuracy of cardiovascular imaging modalities. Nonetheless, the role of sex hormones in modulating myocardial perfusion and coronary flow reserve (CFR) is currently unclear. The aim of our study was to assess the impact of female and male sex hormones on myocardial perfusion and CFR.

Methods Rest and stress myocardial perfusion imaging (MPI) was conducted by small animal positron emission tomography (PET) with $\left[{ }^{18} \mathrm{~F}\right]$ flurpiridaz in a total of 56 mice (7-8 months old) including gonadectomized (Gx) and sham-operated males and females, respectively. Myocardial $\left[{ }^{18} \mathrm{~F}\right]$ flurpiridaz uptake (\% injected dose per $\left.\mathrm{mL}, \% \mathrm{ID} / \mathrm{mL}\right)$ was used as a surrogate for myocardial perfusion at rest and following intravenous regadenoson injection, as previously reported. Apparent coronary flow reserve $\left(\mathrm{CFR}_{\mathrm{App}}\right)$ was calculated as the ratio of stress and rest myocardial perfusion. Left ventricular (LV) morphology and function were assessed by cardiac magnetic resonance (CMR) imaging.

Results Orchiectomy resulted in a significant decrease of resting myocardial perfusion (Gx vs. sham, $19.4 \pm 1.0$ vs. $22.2 \pm$ $0.7 \% \mathrm{ID} / \mathrm{mL}, \mathrm{p}=0.034$ ), while myocardial perfusion at stress remained unchanged (Gx vs. sham, $27.5 \pm 1.2 \mathrm{vs} .27 .3 \pm 1.2$ $\% \mathrm{ID} / \mathrm{mL}, \mathrm{p}=0.896)$. Accordingly, $\mathrm{CFR}_{\mathrm{App}}$ was substantially higher in orchiectomized males (Gx vs. sham, $1.43 \pm 0.04 \mathrm{vs}$. $1.23 \pm 0.05, \mathrm{p}=0.004)$, and low serum testosterone levels were linked to a blunted resting myocardial perfusion $(r=0.438$, $\mathrm{p}=0.020)$ as well as an enhanced $\mathrm{CFR}_{\mathrm{App}}(r=-0.500, \mathrm{p}=0.007)$. In contrast, oophorectomy did not affect myocardial perfusion in females. Of note, orchiectomized males showed a reduced LV mass, stroke volume, and left ventricular ejection fraction (LVEF) on CMR, while no such effects were observed in oophorectomized females.

Conclusion Our experimental data in mice indicate that sex differences in myocardial perfusion are primarily driven by testosterone. Given the diagnostic importance of PET-MPI in clinical routine, further studies are warranted to determine whether testosterone levels affect the interpretation of myocardial perfusion findings in patients.
\end{abstract}

Keywords Rest/stress myocardial perfusion imaging (MPI) $\cdot$ Positron emission tomography $(\mathrm{PET}) \cdot\left[{ }^{18} \mathrm{~F}\right]$ flurpiridaz $\cdot$ Sex hormones $\cdot$ Sex differences $\cdot$ Coronary flow reserve $(\mathrm{CFR})$

\section{Introduction}

This article is part of the Topical Collection on Cardiology.

Simon M. Ametamey and Catherine Gebhard contributed equally to this work.

Catherine Gebhard

Catherine.gebhard@usz.ch

Extended author information available on the last page of the article
Positron emission tomography myocardial perfusion imaging (PET-MPI) is the most commonly used tool for the absolute quantification of myocardial blood flow (MBF). As such, impaired coronary flow reserve (CFR) derived from the ratio of stress and rest MBF by PET-MPI is the current non-invasive reference standard for the detection of coronary microvascular dysfunction [1]. Recently, $\left[{ }^{18} \mathrm{~F}\right]$ flurpiridaz was introduced as a novel tracer for PET-MPI [2, 3]. 
$\left[{ }^{18} \mathrm{~F}\right]$ flurpiridaz is a valid alternative to conventional PETMPI tracers owing to its high myocardial extraction across a wide range of achievable flows, as well as its high spatial resolution [4]. The relatively long physical half-life of $\left[{ }^{18} \mathrm{~F}\right]$ flurpiridaz obviates the need for an on-site cyclotron and allows treadmill stress testing. Of note, $\left[{ }^{18} \mathrm{~F}\right]$ flurpiridaz PET proved to be particularly accurate for CFR measurements in patient populations where tissue attenuation correction is challenging - including women and obese patients suggesting that challenges of tissue attenuation correction can be overcome by the relatively high spatial resolution of images obtained with $\left[{ }^{18} \mathrm{~F}\right]$ flurpiridaz [3].

Molecular mechanisms affecting coronary microcirculation are still under investigation and care must be taken in the interpretation of decreased CFR values. Previous studies have reported sex differences in the prognostic value of PETderived CFR [5] as well as higher resting MBF in asymptomatic women as compared to men [6]. Moreover, two previous studies indicate that coronary flow velocity reserve, which is an invasive measure of microvascular function, was lower in women with chest pain and unobstructed coronary arteries than in their male counterparts [7, 8]. Despite these documented sex differences, little is known about the effect of sex hormones on MBF and CFR. Therefore, the aim of our study was to investigate the impact of gonadectomy on myocardial perfusion and flow reserve in mice using $\left[{ }^{18} \mathrm{~F}\right]$ flurpiridaz PET-MPI.

\section{Methods}

\section{Gonadectomy}

Female and male FVB/N mice were purchased from Janvier Labs (France). Prior to shipment, animals were randomized into subgroups that were subjected to either sham-surgery or gonadectomy $(\mathrm{Gx})$ at the age of one month. All animal experiments were performed in accordance with the Swiss animal welfare laws and were approved by the Cantonal Veterinary Office of Zurich (Switzerland). Mice were housed under specific pathogen-free conditions in individually ventilated cages with continuous free access to water and food ad libitum.

\section{Rest/stress myocardial perfusion imaging}

$\left[{ }^{18} \mathrm{~F}\right]$ Flurpiridaz PET was conducted in a total of 56 animals (7-8 months) that were anesthetized with $1.3-1.9 \%$ isoflurane in oxygen-enriched air (1:1). Body temperature was monitored with a small rectal thermistor. $\left[{ }^{18} \mathrm{~F}\right]$ Flurpiridaz was administered via tail-vein injection $60 \mathrm{~s}$ after scan start (0.6-8.2 MBq). Tracer distribution was recorded in dynamic PET acquisition mode over a time period of $41 \mathrm{~min}$, before a mixture of regadenoson $(0.1 \mu \mathrm{g} / \mathrm{g})$, and a second dose of $\left[{ }^{18} \mathrm{~F}\right]$ flurpiridaz was injected via a pre-installed intravenous catheter. In analogy to the rest scans, stress scans were acquired for $41 \mathrm{~min}$. PET imaging was performed with a Super Argus PET/CT tomography (Sedecal, Spain), followed by a CT scan for anatomical information. PET data were reconstructed with a user-defined protocol at a voxel size of $0.3875 \times 0.3875 \times 0.775 \mathrm{~mm}^{3}$. PET data were processed with PMOD v.3.8 (PMOD Technologies, Switzerland). A volume of interest (VOI) delineating the myocardium was drawn manually by PMOD v.3.8 (PMOD Technologies, Switzerland). Average myocardial $\left[{ }^{18} \mathrm{~F}\right]$ flurpiridaz uptake from 20 to 40 min post injection, calculated from $\%$ injected dose per $\mathrm{mL}$ of the myocardium $(\% \mathrm{ID} / \mathrm{mL})$, was used as a surrogate for myocardial perfusion at rest and following intravenous regadenoson injection, as previously reported [9]. Apparent coronary flow reserve $\left(\mathrm{CFR}_{\mathrm{App}}\right)$ was calculated as the ratio between myocardial $\left[{ }^{18} \mathrm{~F}\right]$ flurpiridaz uptake following vasodilator stress and at resting conditions. The term "apparent" is used because $\mathrm{CFR}_{\mathrm{App}}$ values were calculated without an arterial input function [9].

\section{Cardiac magnetic resonance (CMR)}

Mice were initially anesthetized with isoflurane (1.8-2.5\%) in oxygen-enriched air. Body temperature was monitored with a small rectal thermistor probe (ERT model 1030 control/gating module, Small Animal Instruments Inc, USA) and maintained at $36-37^{\circ} \mathrm{C}$ using a warm-water circuit. All MRI experiments were performed on a Bruker BioSpec 70/30 USR magnetic resonance scanner (Bruker BioSpin MRI, Germany), equipped with a $1 \mathrm{H}$ receive-only $2 \times 2$ mouse cardiac surface array coil (Bruker BioSpin AG, Switzerland) and a Bruker console running ParaVision 6.0.1 (Bruker Cooperation, USA). For the two-chamber view of the LV long axis (LA), a cine-fast low angle shot (CineFLASH) sequence with simultaneous respiratory self-gating was performed using the following parameters: Field of view $(\mathrm{FOV})=25 \mathrm{~mm} \times 25 \mathrm{~mm}$, matrix dimension $(\mathrm{MD})=192 \times$ 192 , slice thickness $(\mathrm{STH})=0.8 \mathrm{~mm}$, flip angle $(\mathrm{FA})=15$, repetition time $(\operatorname{ReT})=8 \mathrm{~ms}$, echo time $(\mathrm{ET})=2.4 \mathrm{~ms}$, number of averages (NA) $=8$ resulting in 12 frames. The longest distance of the LV cavity was determined between the mitral valves and the most apical point of the LV cavity. This length was used to plan subsequent coronal Cine-FLASH short axis (SA) scans. LVEF and stroke volume (SV) were calculated according to the modified Simpson rule at 1/3 (Am) and 2/3 (Ap) of the LV length [10].

\section{Heart rate reserve}

Heart rate was monitored during CMR imaging by electrocardiogram (ECG) electrodes that were inserted 
subcutaneously into the paws of anesthetized animals (1.8-2.5\% isoflurane in oxygen-enriched air) and recorded using SAII monitoring software (Small Animal Instruments Inc, USA). Heart rate was measured at rest and following pharmacological stress (5 min after regadenoson injection, $0.1 \mu \mathrm{g} / \mathrm{g}$ bodyweight). Heart rate reserve (HRR), calculated as $\left(\mathrm{HR}_{\text {Stress }}-\mathrm{HR}_{\text {Rest }}\right) / \mathrm{HR}_{\text {Rest }} * 100$, was used to assess cardiac autonomic function, as previously reported in humans and mice $[11,12]$.

\section{Quantification of circulating sex hormones}

Sex hormone levels were measured using commercially available ELISA kits, according to the manufacturer's recommendation (Calbiotech, USA). The absorbance was determined at a wavelength of $450 \mathrm{~nm}$ and $570 \mathrm{~nm}$ for the pathlength correction using a Tecan infinite pro 200 reader (Tecan, Switzerland). A 4-parameter logistic regression algorithm was used to fit the standard curve. Mean sample hormone concentrations were calculated in a standard range of $0.1-18 \mathrm{ng} / \mathrm{mL}$ for testosterone. Progesterone levels were determined by LC-MS/MS, as previously reported [13].

\section{Statistical analysis}

All statistical analyses were carried out with IBM SPSS Statistics 25 (IBM Corp., USA). Continuous variables are presented as mean \pm standard error of the mean (SEM). Analysis of variance (ANOVA) and Student's t-test were used for group comparisons of continuous variables. Strength and direction of associations were assessed by Spearman's rankorder correlation. A p-value of $\leq 0.05$ (two-tailed) was considered statistically significant.

\section{Results}

\section{Orchiectomy is associated with reduced baseline myocardial perfusion and elevated CFR $_{\text {App }}$}

Gonadectomy was confirmed by assessment of serum sex hormone levels as well as by visual confirmation of the absence of testicular tissue in male mice and the absence of ovarian tissue in female mice at the time of organ harvesting. Testosterone levels were diminished in gonadectomized males, while progesterone serum concentrations were substantially reduced in gonadectomized females (Supplemental Fig. 1). Regadenoson administration resulted in fast coronary vasodilation, leading to an enhanced myocardial perfusion across all animal groups. At rest, sham males displayed a significantly higher myocardial perfusion $(22.2 \pm 0.7 \%$ $\mathrm{ID} / \mathrm{mL})$, as compared to gonadectomized males $(19.4 \pm$ $1.0 \% \mathrm{ID} / \mathrm{mL}, p=0.034$, Fig. $1 \mathrm{~A})$. In contrast, orchiectomy did not affect stress myocardial perfusion, as evidenced by the comparable myocardial $\left[{ }^{18} \mathrm{~F}\right]$ flurpiridaz uptake in both groups (Gx vs. sham, $27.5 \pm 1.2$ vs. $27.3 \pm 1.2 \% \mathrm{ID} / \mathrm{mL}, p$ $=0.896$, Fig. 1B). Consequently, $\mathrm{CFR}_{\mathrm{App}}$ calculated as the ratio of stress to resting myocardial perfusion, was higher in gonadectomized males as compared to sham males ( $\mathrm{Gx}$ vs. sham, $1.43 \pm 0.04$ vs. $1.23 \pm 0.05, p=0.004$, Fig. 1C). Oophorectomy had no influence on baseline myocardial perfusion (Gx vs. sham, $21.1 \pm 1.1$ vs. $21.0 \pm 1.2 \% \mathrm{ID} / \mathrm{mL}$, $p=0.965$, Fig. 1D). Although there was a trend toward an attenuated myocardial perfusion at stress in gonadectomized females, this difference did not reach statistical significance (Gx vs. sham, $28.8 \pm 1.2$ vs. $30.8 \pm 1.8 \% \mathrm{ID} / \mathrm{mL}, p=0.384$, Fig. 1E). In concert, oophorectomy did not alter $\mathrm{CFR}_{\mathrm{App}}$ in females (Gx vs. sham, $1.40 \pm 0.07$ vs. $1.48 \pm 0.05, p=$ 0.365 , Fig. 1F). A one-way ANOVA revealed that baseline $\mathrm{CFR}_{\text {App }}$ values were significantly higher in sham females than sham males (female vs. male, $1.48 \pm 0.05$ vs. $1.23 \pm$ $0.05, p=0.013$ ), which was not the case for gonadectomized animals (female vs. male, $1.40 \pm 0.07$ vs. $1.43 \pm 0.04, p$ $=0.951)$. Representative baseline and hyperemic PET-MPI images of the male myocardium are depicted in Fig. 2.

\section{Autonomic function is altered in gonadectomized males}

Baseline heart rate was significantly higher in gonadectomized vs. sham males ( $517 \pm 7$ vs. $462 \pm 13$ bpm, $p=0.001$, Fig. 3A), while this effect of gonadectomy on heart rate was not observed following administration of regadenoson (sham vs. Gx, $530 \pm 11$ vs. $537 \pm 6$ bpm, $p=0.588$, Fig. $3 \mathrm{~B}$ ). Heart rate reserve during pharmacological stress was significantly higher in sham vs. gonadectomized males $(11 \pm 2$ vs. $5 \pm 1 \%, p=0.002$, Fig. 3C). Conversely, gonadectomy did not have an effect on heart rate reserve in female animals, as evidenced by the comparable heart rate at baseline and following vasodilator stress (Fig. 3D-F).

\section{Effect of gonadectomy on myocardial function}

No significant differences in body weight were observed between gonadectomized and sham animals (Supplemental Fig. 2A and D) in both males and females. Orchiectomy led to a significant reduction of $\mathrm{LV}$ mass in males (sham vs. Gx, $0.083 \pm 0.003$ vs. $0.073 \pm 0.003 \mathrm{~g}, \mathrm{p}=0.026$, Fig. $4 \mathrm{~A}$ ), while this effect was not observed following oophorectomy in females $(0.069 \pm 0.002$ vs. $0.066 \pm 0.004 \mathrm{~g}, \mathrm{p}=0.439$, Fig. 4D). Further, orchiectomy resulted in a reduction of CMR-derived left ventricular stroke volume (sham vs. Gx, $40 \pm 2$ vs. $35 \pm 1 \mu \mathrm{L}, p=0.010$, Fig. 4B) and LVEF (sham vs. Gx, $68 \pm 2$ vs. $62 \pm 2 \%, p=0.042$, Fig. 4 C). The gonadectomy-induced decrease of LVEF in males was a consequence of slightly enhanced end-systolic volumes 
A

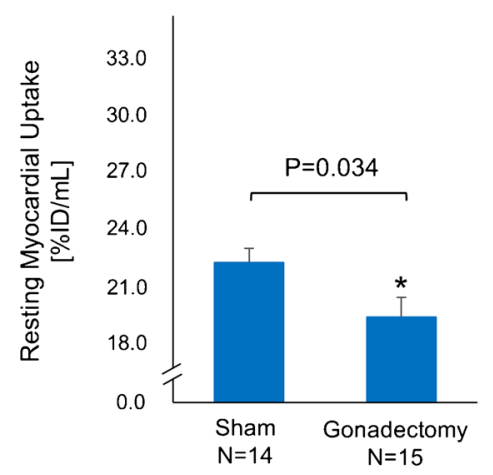

D

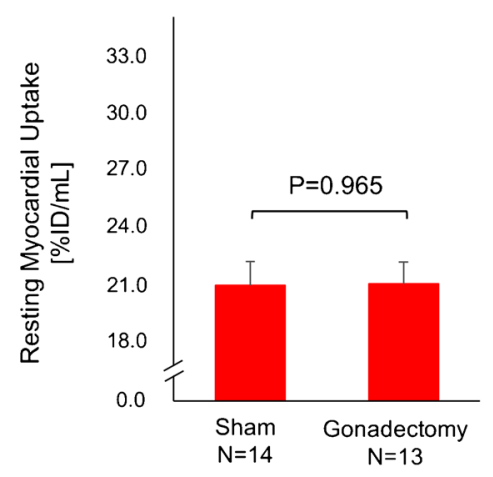

B

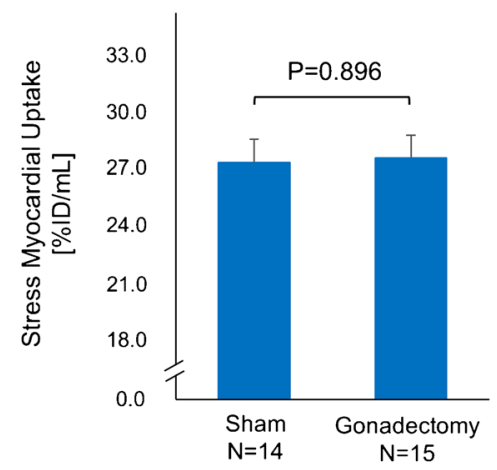

$\mathrm{E}$

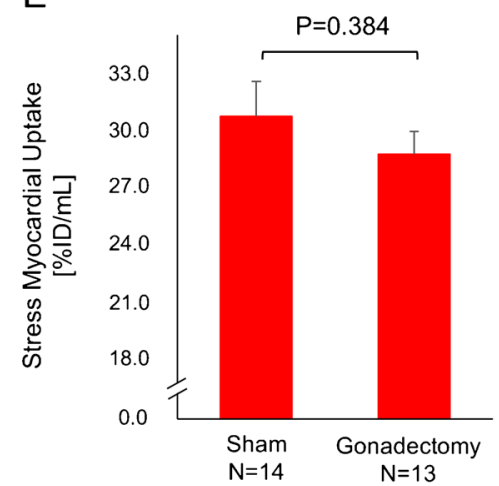

C

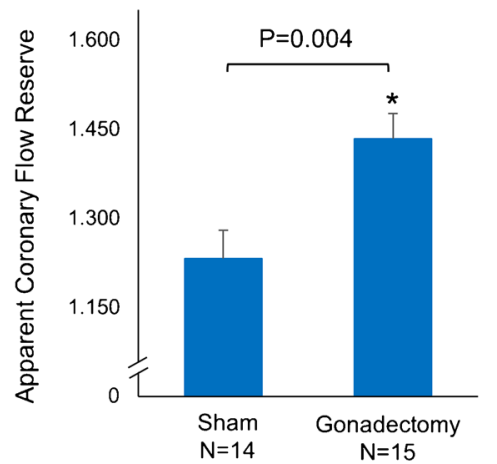

$\mathrm{F}$

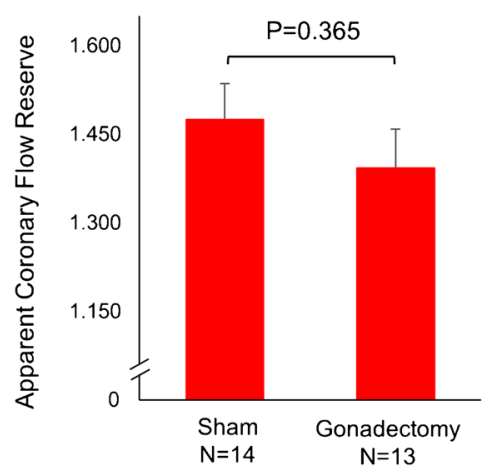

Fig. 1 Rest/stress myocardial perfusion imaging by small animal positron emission tomography (PET). (A) Resting myocardial perfusion in males. (B) Stress myocardial perfusion in males. (C) Appar- ent coronary flow reserve $\left(\mathrm{CFR}_{\mathrm{App}}\right)$ in males. (D) Resting myocardial perfusion in females. (E) Stress myocardial perfusion in females. $(\mathbf{F})$ Apparent coronary flow reserve $\left(\mathrm{CFR}_{\mathrm{App}}\right)$ in females
Fig. 2 Representative positron emission tomography (PET) images of the mouse myocardium at rest and following pharmacological stress in sham and gonadectomized $(\mathrm{Gx})$ males. (A) Sham, rest-MPI; (B) Gx, rest-MPI; (C) sham, stress-MPI; (D) Gx, stress-MPI
Rest PET-MPI

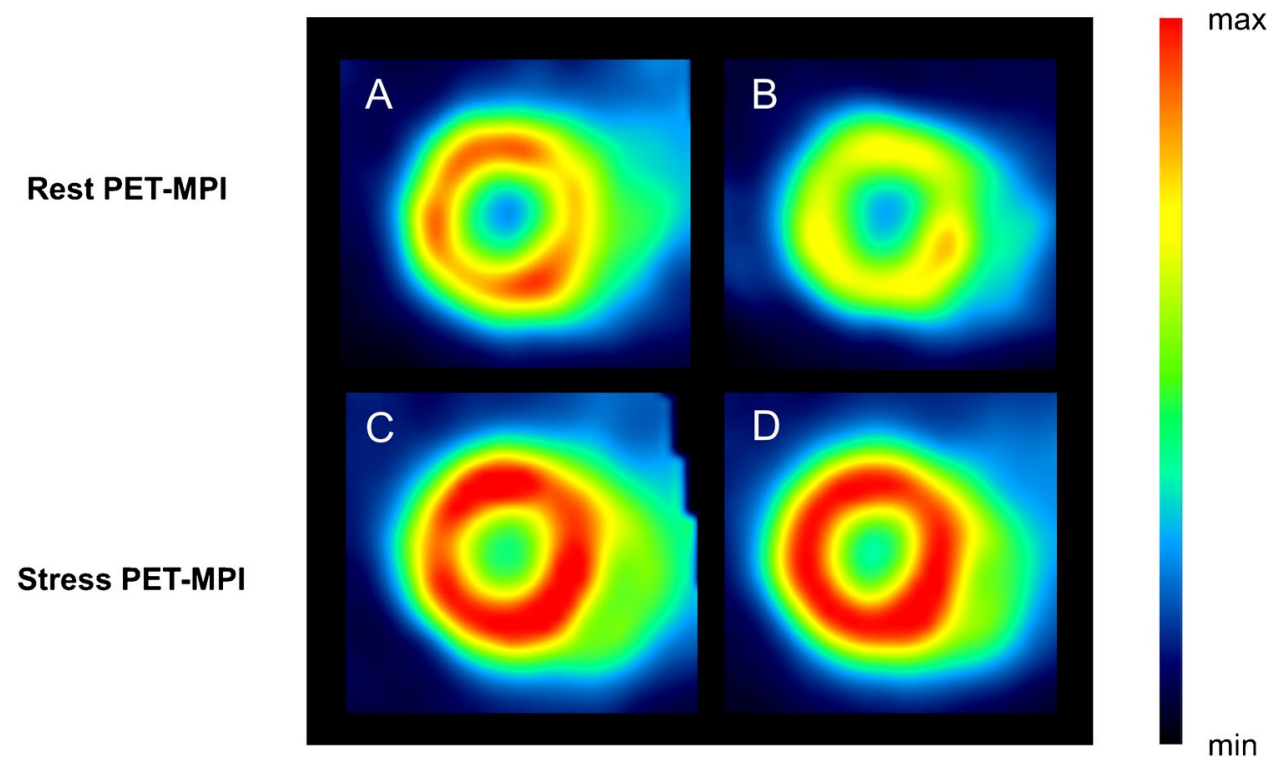

$\max$ along with moderately decreased end-diastolic volumes in gonadectomized males (Supplemental Fig. 2B and C). In contrast, oophorectomy did not affect stroke volume (sham vs. Gx, $35 \pm 1$ vs. $33 \pm 1 \mu \mathrm{L}, p=0.456$, Fig. $4 \mathrm{E}$ ) and LVEF (sham vs. Gx, $66 \pm 2$ vs. $65 \pm 2 \%, p=0.921$, Fig. $4 \mathrm{~F}$ ) in our study. 
A

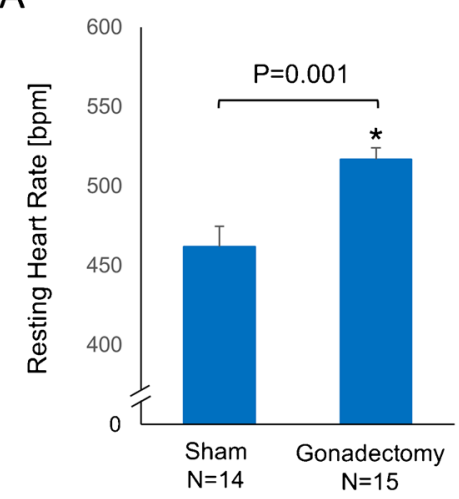

D

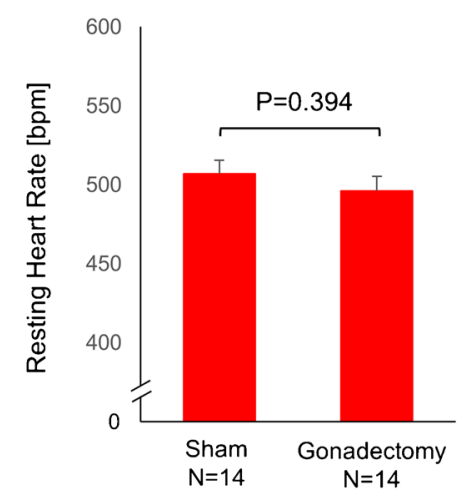

B

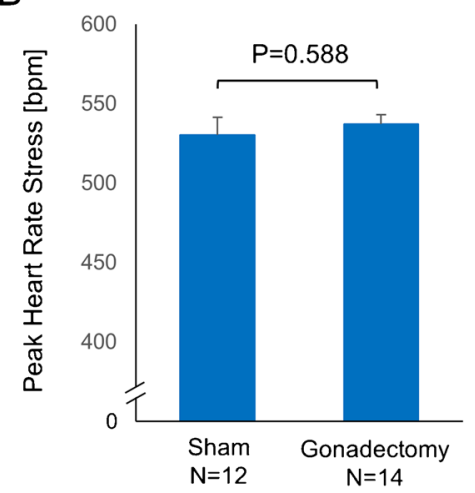

$E$

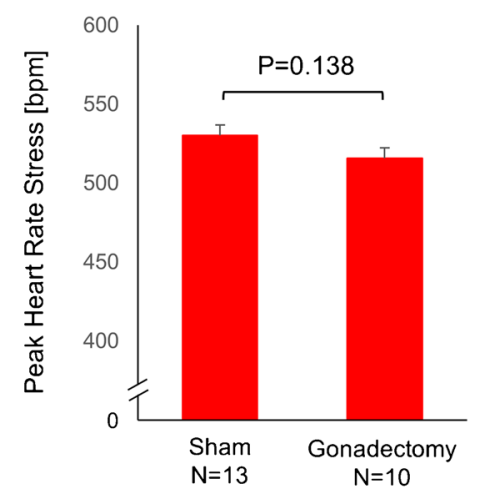

C

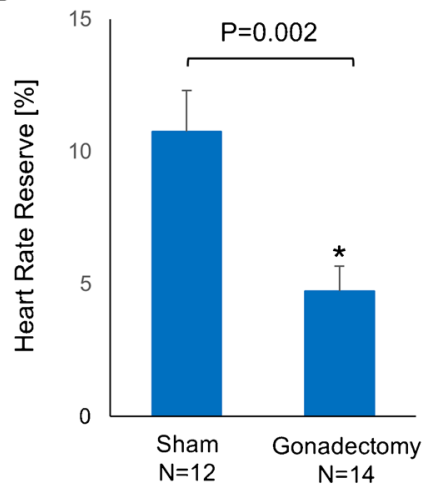

F

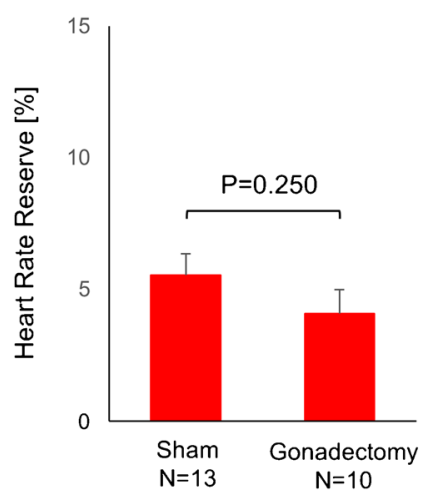

Fig. 3 Heart rate and heart rate variability. (A) Baseline heart rate in males. (B) Stress heart rate in males. (C) Heart rate reserve in males. (D) Baseline heart rate in females. (E) Stress heart rate in females. (F) Heart rate reserve in females

\section{Testosterone serum levels are associated with resting heart rate and myocardial perfusion}

Low serum testosterone levels were associated with a blunted resting myocardial perfusion $(r=0.438, p=0.020)$ and enhanced baseline heart rate in males $(r=-0.526, \mathrm{p}=$ 0.004 , Table 1). Similarly, serum testosterone levels significantly correlated with $\mathrm{CFR}_{\mathrm{App}}(r=-0.500, p=0.007)$ and with heart rate reserve $(r=0.430, p=0.032)$.

\section{Discussion}

In the present experimental study, withdrawal of male, but not female, sex hormones increased $\mathrm{CFR}_{\mathrm{App}}$, which was driven by a substantial reduction in resting myocardial perfusion. Accordingly, serum testosterone levels in male mice significantly correlated with resting myocardial perfusion and $\mathrm{CFR}_{\mathrm{App}}$ on PET-MPI. Our results indicate that the reduced resting myocardial perfusion observed in testosterone-deprived males might be the consequence of a blunted HRR in these mice, which typically reflects an impaired cardiac autonomic function (e.g., reduced cardiac sympathetic outflow). Along this line, the reduction in myocardial perfusion was linked to a reduced cardiac function on CMR, as evidenced by the reduced stroke volumes and LVEF in testosterone-deprived males. The concept that reduced baseline myocardial perfusion is a secondary effect of cardiac remodeling processes was further supported by the notion that orchiectomy, but not oophorectomy, prompted a significant reduction in LV mass, while no differences in body weight were observed between experimental groups.

Consistent with our findings, previous reports have linked high testosterone hormone levels to an increased coronary vasodilation. As such, testosterone was found to trigger vasodilation in an in vitro study in isolated rabbit coronary arteries [14]. Similarly, administration of testosterone resulted in dilated coronary arteries in anesthetized male and female dogs $[15,16]$. Further, intracoronary administration of physiological androgen doses in male pigs induced vasodilation and increased coronary blood flow [17]. In contrast to previous reports, however, our study is the first to compare the effects of oophorectomy and orchiectomy on myocardial perfusion in vivo by PET-MPI using $\left[{ }^{18} \mathrm{~F}\right]$ flurpiridaz, which to date provides the highest spatial resolution among contemporary PET-MPI probes. Further, by performing rest 
A

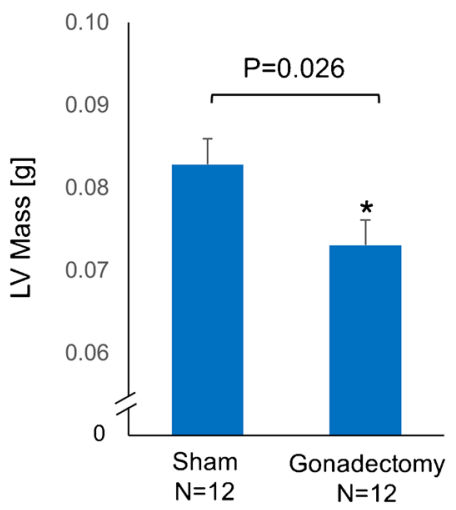

D

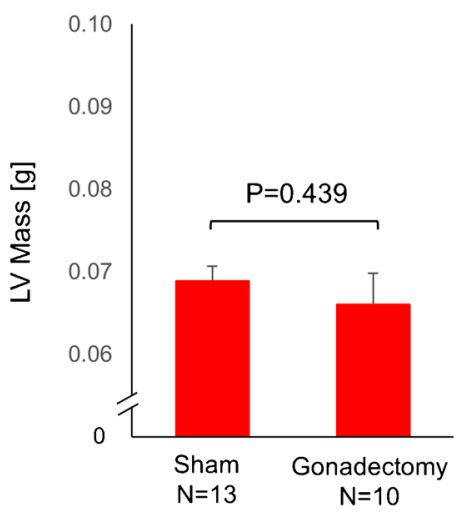

B

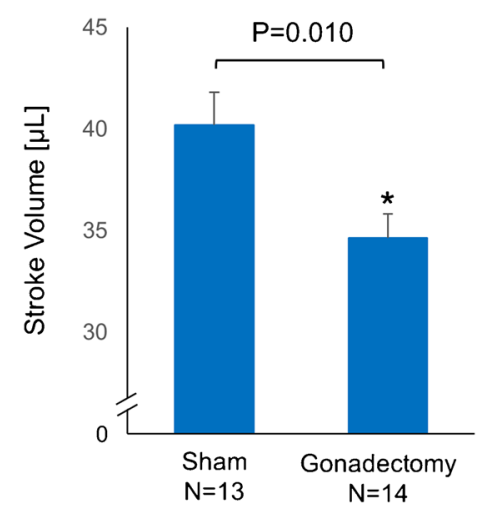

E

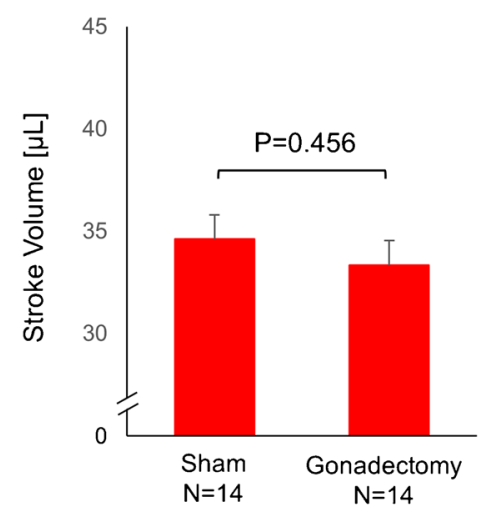

C

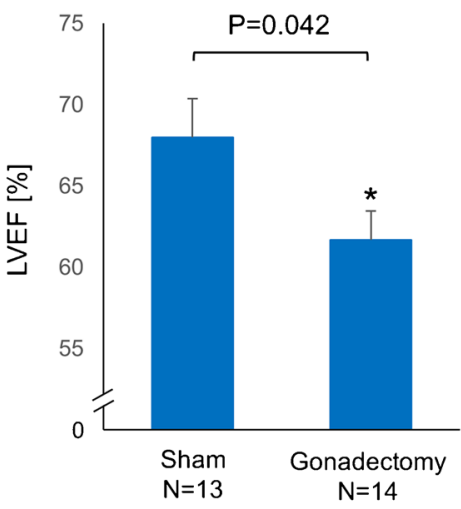

$\mathrm{F}$

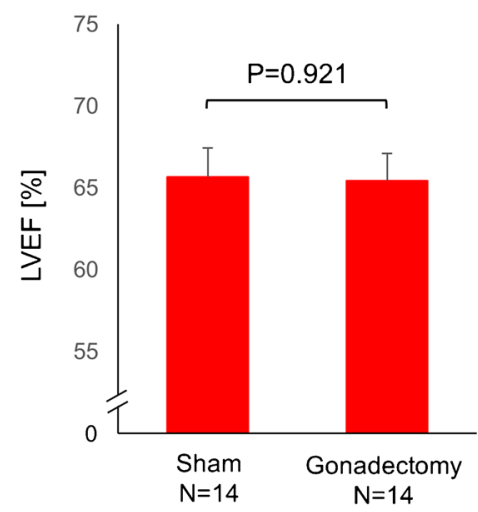

Fig. 4 Cardiac magnetic resonance (CMR) imaging-derived left ventricular (LV) mass and function. (A) LV mass in males. (B) Stroke volume in males. (C) Left ventricular ejection fraction (LVEF) in males. (D) LV mass in females. (E) Stroke volume in females. (F) LVEF in females

Table 1 Correlation of serum testosterone levels with key parameters of myocardial perfusion and heart rate variability in the male study population

\begin{tabular}{lllllll}
\hline Parameter & $\begin{array}{l}\text { Resting myocar- } \\
\text { dial perfusion }\end{array}$ & $\begin{array}{l}\text { Stress myocardial } \\
\text { perfusion }\end{array}$ & $\begin{array}{l}\text { Apparent coronary } \\
\text { flow reserve }\end{array}$ & Resting heart rate & Stress heart rate & Heart rate reserve \\
\hline$r$ (Spearman) & $\mathbf{0 . 4 3 8}$ & 0.041 & $\mathbf{- 0 . 5 0 0}$ & $\mathbf{- 0 . 5 2 6}$ & -0.154 & $\mathbf{0 . 4 3 0}$ \\
P value & $\mathbf{0 . 0 2 0}$ & 0.835 & $\mathbf{0 . 0 0 7}$ & $\mathbf{0 . 0 0 4}$ & 0.452 & $\mathbf{0 . 0 3 2}$ \\
$\mathrm{N}$ & 28 & 28 & 28 & 28 & 26 & 26 \\
\hline
\end{tabular}

and stress PET-MPI, we demonstrate that the vasodilatory effect of testosterone translated into increased myocardial perfusion at resting conditions, but not following injection of the pharmacological stressor. While the pharmacological stressor prompted maximal vasodilation, independent of testosterone levels, our findings imply that testosterone may act as a key modulator of $\mathrm{CFR}_{\mathrm{App}}$ by selectively increasing resting myocardial perfusion. Along this line, high testosterone exposure in sham males may have resulted in the observed sex difference in $\mathrm{CFR}_{\mathrm{App}}$ values for sham animals as the latter was reversed by gonadectomy.
In agreement with previous reports, we found that low testosterone was associated with a reduction of LV mass $[18,19]$. The latter may have contributed to the attenuated cardiac contractility in orchiectomized males as evidenced by their blunted stroke volumes. Of note, we observed that these changes were associated with an increase in baseline heart rate, which points toward a chronotropic adaptation to reduced cardiac contractility. Similarly, the attenuated baseline myocardial perfusion in orchiectomized males can be explained by a decreased blood supply as a consequence of a blunted HRR. Nonetheless, our study does not address 
the question whether lower resting myocardial perfusion in sham males results from a direct coronary vasodilatory effect of testosterone or whether it is the manifestation of distinct LV remodeling processes in sham vs. orchiectomized males.

To date, few exploratory clinical studies have assessed the role of female sex steroids on myocardial perfusion and CFR. In agreement with our findings, Campisi et al. found that short- and long-term administration of $17 \beta$-estradiol did not affect myocardial perfusion [20]. Similarly, Schwitter et al. demonstrated that 3-month oral administration of $17 \beta$-estradiol did not influence CFR, HR, or resting coronary sinus blood flow in postmenopausal women free of coronary artery disease (CAD) [21]. Moreover, administration of combined hormonal therapy (estrogen and progestin) to postmenopausal women at risk for CAD had no effect on CFR or myocardial perfusion [22]. Clinical studies assessing the association between testosterone and myocardial perfusion are limited. Consistent with our data, increased myocardial perfusion in areas supplied by unobstructed coronaries was detected by MRI following oral administration of testosterone for 8 weeks in 22 men with coronary artery disease [23]. These findings support the notion that testosterone may contribute to coronary vasodilation and an improved baseline perfusion of the healthy myocardium [24]. Nonetheless, other studies unveiled that testosterone administration increased the risk of major adverse cardiovascular events (MACE) [25-29]. Despite initial efforts to elucidate the role of sex hormones on myocardial perfusion, prospective clinical trials encompassing healthy individuals and CAD patients are currently lacking.

Previous studies in healthy individuals and patients with suspected CAD indicated that baseline myocardial blood flow is higher in women than in men $[1,6]$. Conversely, we did not detect any sex differences in baseline myocardial perfusion in our mouse model. These seemingly divergent findings may be attributed to the age of the animals in our cohort. Indeed, while we used relatively young mice with high physiological sex hormone concentrations, the vast majority of reported clinical cardiovascular studies encompassed men at an advanced age with unknown testosterone levels. Given that testosterone substantially declines with age in men [30], it is conceivable that the attenuated testosterone levels in elderly men may have contributed to the lower MBF observed in these studies. Our findings further imply that caution is warranted with regard to the interpretation of PET-MPI findings in patients with testosterone levels outside of the physiological range and patients receiving androgen deprivation therapy. Notwithstanding the reported sex differences in baseline and hyperemic MBF, Murthy et al. found similar CFR values in men and women with suspected CAD [1]. The average age in the latter study was 61.2 years for men and 62.3 years for women, suggesting that these individuals had reduced sex hormone levels. Along this line, sex differences in $\mathrm{CFR}_{\mathrm{App}}$ were only observed in sham animals and diminished following gonadectomy in our study. While a CFR $<2.0$ is considered abnormal in humans according to current ECS guidelines [31] and is a strong predictor of major adverse cardiac events in both sexes [1], there are no such reference values for rodents. In fact, reported CFR values in healthy rodents can range from 1.4 to 3.2 [32-36]. The latter variability can be, at least in part, attributed to the distinct imaging modalities employed for small-animal MPI. Notably, although PET-MPI is the reference standard for CFR measurements in humans, studies on CFR measurements with rest/stress PET-MPI in rodents are scarce, potentially owing to technical challenges that result from the short half-life of conventional PET-MPI probes including $\left[{ }^{13} \mathrm{~N}\right]$ ammonia and $\left[{ }^{15} \mathrm{O}\right]$ water. We anticipate that the availability of $\left[{ }^{18} \mathrm{~F}\right]$ flurpiridaz, which allows PET-MPI in research facilities without an on-site cyclotron, will lead to an increased use of PET-MPI in rodents, thereby providing a valuable tool for CFR quantification by small animal imaging in future studies. Other factors that may directly or indirectly affect the measurement of CFR include the underlying animal strain, sex, and age. Indeed, our findings imply that sex hormones significantly affect the measurement of CFR. Similarly, others have observed age-dependent changes of myocardial perfusion and CFR in mice [36]. These findings underscore the challenge of defining CFR reference values in rodents.

There are limitations to this study that should be noted. First, the findings obtained from this study are based on rodent data and may not be directly extrapolated to humans. However, previous reports have shown that testosteronemediated regulation of autonomic function seems to be largely conserved across species [37-39]. Second, although high concentrations of isoflurane may exert coronary vasodilator properties [40], studies have shown that mean systolic blood pressure and heart rate remain stable at isoflurane concentration up to $2 \%$ in mice [41, 42]. Accordingly, to minimize the vasodilating effect of isoflurane, concentrations were kept below $2 \%$ throughout all experiments. Third, perfusion changes in other organs may have affected the systemic $\left[{ }^{18} \mathrm{~F}\right]$ flurpiridaz availability, and thus tracer delivery to the myocardium. Indeed, regadenoson-induced changes in abdominal arterial flow may have resulted in an overall underestimation of the $\mathrm{CFR}_{\mathrm{App}}$ values in our study. In the absence of an arterial input function, the latter cannot be excluded. Nonetheless, $\left[{ }^{18} \mathrm{~F}\right]$ flurpiridaz exhibits higher uptake values in the heart compared to most other major organs, which limits the influence of extracardiac perfusion variability [43]. Finally, while our study shows an association of testosterone serum levels with resting myocardial perfusion, $\mathrm{CFR}_{\mathrm{App}}$ and baseline heart rate, establishing causality warrants further investigations into molecular 
pathways that translate testosterone effects into changes in coronary vasoregulation and cardiac adrenergic signaling.

In conclusion, our results indicate that sex differences in myocardial perfusion are primarily driven by testosterone. While orchiectomy and blunted serum testosterone levels were associated with a reduced baseline myocardial perfusion and an enhanced $\mathrm{CFR}_{\mathrm{App}}$, respectively, these findings were not observed in females. To the best of our knowledge, this is the first study assessing the effect of orchiectomy and oophorectomy on myocardial perfusion and flow reserve using small animal PET. With regard to the translational relevance of the present findings, accounting for the variability in testosterone exposure may help to improve diagnostic accuracy of PET-derived CFR in specific patient populations and identify patient subpopulations that profit most from this diagnostic modality.

Supplementary Information The online version contains supplementary material available at https://doi.org/10.1007/s00259-022-05675-2.

Funding Open access funding provided by University of Zurich. CG was supported by grants from the Swiss National Science Foundation (SNSF), the Olga Mayenfisch Foundation, Switzerland, the OPO Foundation, Switzerland, the Novartis Foundation, Switzerland, the Swiss Heart Foundation, the Helmut Horten Foundation, Switzerland, the EMDO Foundation, Switzerland, and the Iten-Kohaut Foundation, Switzerland. SB and AH were supported by the University of Zurich (UZH) Foundation. SB was supported by the Swiss Heart Foundation.

\section{Declarations}

Conflict of interest All authors have the following to disclose: The University Hospital of Zurich holds a research contract with GE Healthcare. CG has received research grants from the Novartis Foundation, Switzerland.

Open Access This article is licensed under a Creative Commons Attribution 4.0 International License, which permits use, sharing, adaptation, distribution and reproduction in any medium or format, as long as you give appropriate credit to the original author(s) and the source, provide a link to the Creative Commons licence, and indicate if changes were made. The images or other third party material in this article are included in the article's Creative Commons licence, unless indicated otherwise in a credit line to the material. If material is not included in the article's Creative Commons licence and your intended use is not permitted by statutory regulation or exceeds the permitted use, you will need to obtain permission directly from the copyright holder. To view a copy of this licence, visit http://creativecommons.org/licenses/by/4.0/.

\section{References}

1. Murthy VL, Naya M, Taqueti VR, Foster CR, Gaber M, Hainer $\mathrm{J}$, et al. Effects of sex on coronary microvascular dysfunction and cardiac outcomes. Circulation. 2014;129:2518-27. https://doi.org/ 10.1161/circulationaha.113.008507.

2. Berman DS, Maddahi J, Tamarappoo BK, Czernin J, Taillefer R, Udelson JE, et al. Phase II safety and clinical comparison with single-photon emission computed tomography myocardial perfusion imaging for detection of coronary artery disease: flurpiridaz F 18 positron emission tomography. J Am Coll Cardiol. 2013;61:46977. https://doi.org/10.1016/j.jacc.2012.11.022.

3. Maddahi J, Lazewatsky J, Udelson JE, Berman DS, Beanlands RSB, Heller GV, et al. Phase-III clinical trial of fluorine-18 flurpiridaz positron emission tomography for evaluation of coronary artery disease. J Am Coll Cardiol. 2020;76:391-401. https:// doi.org/10.1016/j.jacc.2020.05.063.

4. Nekolla SG, Reder S, Saraste A, Higuchi T, Dzewas G, Preissel A, et al. Evaluation of the novel myocardial perfusion positronemission tomography tracer 18F-BMS-747158-02: comparison to $13 \mathrm{~N}$-ammonia and validation with microspheres in a pig model. Circulation. 2009;119:2333-42. https://doi.org/10.1161/circulatio naha.108.797761.

5. Gebhard C, Fiechter M, Herzog BA, Lohmann C, Bengs S, Treyer $\mathrm{V}$, et al. Sex differences in the long-term prognostic value of (13) $\mathrm{N}$-ammonia myocardial perfusion positron emission tomography. Eur J Nucl Med Mol Imaging. 2018;45:1964-74. https://doi.org/ 10.1007/s00259-018-4046-8.

6. Chareonthaitawee P, Kaufmann PA, Rimoldi O, Camici PG. Heterogeneity of resting and hyperemic myocardial blood flow in healthy humans. Cardiovasc Res. 2001;50:151-61. https://doi.org/ 10.1016/s0008-6363(01)00202-4.

7. Han SH, Bae JH, Holmes DR Jr, Lennon RJ, Eeckhout E, Barsness $\mathrm{GW}$, et al. Sex differences in atheroma burden and endothelial function in patients with early coronary atherosclerosis. Eur Heart J. 2008;29:1359-69. https://doi.org/10.1093/eurheartj/ehn142.

8. Kobayashi Y, Fearon WF, Honda Y, Tanaka S, Pargaonkar V, Fitzgerald PJ, et al. Effect of sex differences on invasive measures of coronary microvascular dysfunction in patients with angina in the absence of obstructive coronary artery disease. JACC Cardiovasc Interv. 2015;8:1433-41. https://doi.org/10.1016/j.jcin.2015. 03.045 .

9. Bengs S, Warnock GI, Portmann A, Mikail N, Rossi A, Ahmed $\mathrm{H}$, et al. Rest/stress myocardial perfusion imaging by positron emission tomography with 18F-Flurpiridaz: a feasibility study in mice. bioRxiv. 2021:2021.09.05.459034. https://doi.org/10.1101/ 2021.09.05.459034.

10. Folland ED, Parisi AF, Moynihan PF, Jones DR, Feldman CL, Tow DE. Assessment of left ventricular ejection fraction and volumes by real-time, two-dimensional echocardiography. A comparison of cineangiographic and radionuclide techniques. Circulation. 1979;60:760-6. https://doi.org/10.1161/01.cir.60.4.760.

11. Täng MS, Råmunddal T, Lindbom M, Omerovic E. Native cardiac reserve predicts survival in acute post infarction heart failure in mice. Cardiovasc Ultrasound. 2007;5:46. https://doi.org/10.1186/ 1476-7120-5-46.

12. Haider A, Bengs S, Maredziak M, Messerli M, Fiechter M, Giannopoulos AA, et al. Heart rate reserve during pharmacological stress is a significant negative predictor of impaired coronary flow reserve in women. Eur J Nucl Med Mol Imaging. 2019;46:125767. https://doi.org/10.1007/s00259-019-4265-7.

13. Gaudl A, Kratzsch J, Bae YJ, Kiess W, Thiery J, Ceglarek U. Liquid chromatography quadrupole linear ion trap mass spectrometry for quantitative steroid hormone analysis in plasma, urine, saliva and hair. J Chromatogr A. 2016;1464:64-71. https://doi.org/10. 1016/j.chroma.2016.07.087.

14. Yue P, Chatterjee K, Beale C, Poole-Wilson PA, Collins P. Testosterone relaxes rabbit coronary arteries and aorta. Circulation. 1995;91:1154-60. https://doi.org/10.1161/01.CIR.91.4.1154.

15. Chou TM, Sudhir K, Hutchison SJ, Ko E, Amidon TM, Collins P, et al. Testosterone induces dilation of canine coronary conductance and resistance arteries in vivo. Circulation. 1996;94:2614-9. https://doi.org/10.1161/01.CIR.94.10.2614. 
16. Gagliano-Jucá T, Basaria S. Testosterone replacement therapy and cardiovascular risk. Nat Rev Cardiol. 2019;16:555-74. https://doi. org/10.1038/s41569-019-0211-4.

17. O'Connor EK, Ivey JR, Bowles DK. Differential effects of androgens on coronary blood flow regulation and arteriolar diameter in intact and castrated swine. Biol Sex Differ. 2012. https://doi.org/ 10.1186/2042-6410-3-10.

18. Svartberg J, von Mühlen D, Schirmer H, Barrett-Connor E, Sundfjord J, Jorde R. Association of endogenous testosterone with blood pressure and left ventricular mass in men. The Troms $\varnothing$ Study. Eur J Endocrinol. 2004;150:65-71. https://doi.org/10.1530/eje.0. 1500065.

19. Banga S, Heinze-Milne SD, Godin J, Howlett SE. Signs of diastolic dysfunction are graded by serum testosterone levels in aging C57BL/6 male mice. Mech Ageing Dev. 2021;198:111523. https://doi.org/10.1016/j.mad.2021.111523.

20. Campisi R, Nathan L, Pampaloni MH, Schöder H, Sayre JW, Chaudhuri G, et al. Noninvasive assessment of coronary microcirculatory function in postmenopausal women and effects of short-term and long-term estrogen administration. Circulation. 2002. https://doi.org/10.1161/hc0402.102860.

21. Schwitter J, Kozerke S, Bremerich J, Baltes C, Jost CA, Birkhäuser M, et al. Oral administration of $17 \beta$-estradiol over 3 months without progestin co-administration does not improve coronary flow reserve in post-menopausal women: a randomized placebocontrolled cross-over CMR study. J Cardiovasc Magn Reson. 2007. https://doi.org/10.1080/10976640601138730.

22. Duvernoy C, Martin J, Briesmiester K, Bargardi A, Muzik O, Mosca L. Myocardial blood flow and flow reserve in response to hormone therapy in postmenopausal women with risk factors for coronary disease. J Clin Endocrinol Metab. 89:2783-8.

23. Webb CM, Elkington AG, Kraidly MM, Keenan N, Pennell DJ, Collins P. Effects of oral testosterone treatment on myocardial perfusion and vascular function in men with low plasma testosterone and coronary heart disease. Am J Cardiol. 2008;101:618-24. https://doi.org/10.1016/j.amjcard.2007.09.114.

24. Osborne MT, Bajaj NS, Taqueti VR, Gupta A, Bravo PE, Hainer $\mathrm{J}$, et al. Coronary Microvascular Dysfunction Identifies Patients at High Risk of Adverse Events Across Cardiometabolic Diseases. J Am Coll Cardiol. 2017;70:2835-7.

25. Basaria S, Coviello AD, Travison TG, Storer TW, Farwell WR, Jette AM, et al. Adverse events associated with testosterone administration. N Engl J Med. 2010. https://doi.org/10.1056/ nejmoa1000485.

26. Xu L, Freeman G, Cowling BJ, Schooling CM. Testosterone therapy and cardiovascular events among men: a systematic review and meta-analysis of placebo-controlled randomized trials. BMC Med. 2013. https://doi.org/10.1186/1741-7015-11-108.

27. Sharma R, Oni OA, Gupta K, Chen G, Sharma M, Dawn B, et al. Normalization of testosterone level is associated with reduced incidence of myocardial infarction and mortality in men. Eur Heart J. 2015. https://doi.org/10.1093/eurheartj/ehv346.

28. Finkle WD, Greenland S, Ridgeway GK, Adams JL, Frasco MA, Cook MB, et al. Increased risk of non-fatal myocardial infarction following testosterone therapy prescription in men. PLoS One. 2014. https://doi.org/10.1371/journal.pone.0085805.

29. Vigen R, O'Donnell CI, Barón AE, Grunwald GK, Maddox TM, Bradley SM, et al. Association of testosterone therapy with mortality, myocardial infarction, and stroke in men with low testosterone levels. JAMA - J Am Med Assoc. 2013. https://doi.org/10. 1001/jama.2013.280386.

30. Travison TG, Araujo AB, O'Donnell AB, Kupelian V, McKinlay JB. A population-level decline in serum testosterone levels in American men. J Clin Endocrinol Metab. 2007;92:196-202. https://doi.org/10.1210/jc.2006-1375.

31. Knuuti J, Wijns W, Saraste A, Capodanno D, Barbato E, FunckBrentano C, et al. 2019 ESC Guidelines for the diagnosis and management of chronic coronary syndromes: The Task Force for the diagnosis and management of chronic coronary syndromes of the European Society of Cardiology (ESC). Eur Heart J. 2020;41:407-77. https://doi.org/10.1093/eurheartj/ehz425.

32. Gan L-M, Wikström J, Fritsche-Danielson R. Coronary flow reserve from mouse to man-from mechanistic understanding to future interventions. J Cardiovasc Transl Res. 2013;6:715-28. https://doi.org/10.1007/s12265-013-9497-5.

33. Songstad NT, Serrano MC, Sitras V, Johansen D, Ytrehus K, Acharya G. Coronary flow reserve in pregnant rats with increased left ventricular afterload. PLoS One. 2014;9:e102147. https://doi. org/10.1371/journal.pone.0102147.

34. Saraste A, Kytö V, Saraste M, Vuorinen T, Hartiala J, Saukko P. Coronary flow reserve and heart failure in experimental coxsackievirus myocarditis. A transthoracic Doppler echocardiography study. American Journal of Physiology-Heart and Circulatory. Physiology. 2006;291:H871-H5. https://doi.org/10.1152/ajpheart. 01375.2005 .

35. Hartley CJ, Reddy AK, Madala S, Michael LH, Entman ML, Taffet GE. Doppler estimation of reduced coronary flow reserve in mice with pressure overload cardiac hypertrophy. Ultrasound Med Biol. 2008;34:892-901. https://doi.org/10.1016/j.ultrasmedbio. 2007.11.019.

36. Hartley CJ, Reddy AK, Michael LH, Entman ML, Chintalagattu $\mathrm{V}$, Khakoo AY, et al. Coronary flow reserve in mice: effects of age, coronary disease, and vascular loading. Annu Int Conf IEEE Eng Med Biol Soc. 2010;2010:3780-3. https://doi.org/10.1109/ IEMBS.2010.5627571.

37. Angelidis G, Giamouzis G, Karagiannis G, Butler J, Tsougos I, Valotassiou V, et al. SPECT and PET in ischemic heart failure. Heart Fail Rev. 2017. https://doi.org/10.1007/s10741-017-9594-7.

38. Rai V, Sharma P, Agrawal S, Agrawal DK. Relevance of mouse models of cardiac fibrosis and hypertrophy in cardiac research. Mol Cell Biochem. https://doi.org/10.1007/s11010-016-2849-0.

39. Hasenfuss G. Animal models of human cardiovascular disease, heart failure and hypertrophy. Cardiovasc Res. 1998;39:60-76.

40. Constantinides C, Mean R, Janssen BJ. Effects of isoflurane anesthesia on the cardiovascular function of the C57BL/6 mouse. ILAR J Natl Res Council Inst Lab Anim Res. 2011;2:e21.

41. Matsuda Y, Ohsaka K, Yamamoto H, Natsume K, Hirabayashi $\mathrm{S}$, Kounoike M, et al. Comparison of newly developed inhalation anesthesia system and intraperitoneal anesthesia on the hemodynamic state in mice. Biol Pharm Bull. 2007. https://doi.org/10. 1248/bpb.30.1716.

42. Wu J, Bu L, Gong H, Jiang G, Li L, Ma H, et al. Effects of heart rate and anesthetic timing on high-resolution echocardiographic assessment under isoflurane anesthesia in mice. J Ultrasound Med. 2010. https://doi.org/10.7863/jum.2010.29.12.1771.

43. Huisman MC, Higuchi T, Reder S, Nekolla SG, Poethko T, Wester $\mathrm{HJ}$, et al. Initial characterization of an 18F-labeled myocardial perfusion tracer. J Nucl Med. 2008;49:630-6. https://doi.org/10. 2967/jnumed.107.044727.

Publisher's note Springer Nature remains neutral with regard to jurisdictional claims in published maps and institutional affiliations. 


\section{Authors and Affiliations}

\section{Ahmed Haider ${ }^{1,2} \cdot$ Susan Bengs ${ }^{1,2} \cdot$ Angela Portmann $^{1,2} \cdot$ Alexia Rossi $^{1,2} \cdot$ Hazem Ahmed $^{3} \cdot$ Dominik Etter $^{1,2}$. Geoffrey I. Warnock ${ }^{1,2} \cdot$ Nidaa Mikail $^{1,2} \cdot$ Muriel Grämer $^{1,2} \cdot$ Alexander Meisel $^{1,2} \cdot$ Livio Gisler $^{3} \cdot$ Caitlin Jie $^{3}$. Claudia Keller $^{3} \cdot$ Sebastian Kozerke $^{4} \cdot$ Bruno Weber $^{5} \cdot$ Roger Schibli $^{1,3} \cdot$ Linjing Mu$^{1,3} \cdot$ Philipp A. Kaufmann $^{1}$. Vera Regitz-Zagrosek $^{6,7}$. Simon M. Ametamey ${ }^{3}$. Catherine Gebhard ${ }^{1,2}$}

$1 \quad$ Department of Nuclear Medicine, University Hospital Zurich, Raemistrasse 100, CH-8091 Zurich, Switzerland

2 Center for Molecular Cardiology, University of Zurich, CH-8952 Schlieren, Switzerland

3 Institute of Pharmaceutical Sciences, ETH Zurich, CH-8093 Zurich, Switzerland

4 Institute for Biomedical Engineering, University and ETH Zurich, CH-8092 Zurich, Switzerland
5 Institute of Pharmacology and Toxicology, University of Zurich, CH-8057 Zurich, Switzerland

6 Institute for Gender in Medicine, Charité Universitaetsmedizin Berlin, D-10115 Berlin, Germany

7 University Hospital Zurich, CH-8091 Zurich, Switzerland 